\title{
Un nuevo modelo de construcción de paz
}

Recibido: 14.02.2017 / Aprobado: 20.02.2017

Por Dane F. Smith, Jr. *

\author{
La paz siempre está amenazada. ... Es un don de Dios \\ que tiene que ser constantemente mantenido haciendo justicia.
}

José Miguez Bonino

\section{Resumen}

Los cristianos han estado comprometidos en la construcción de paz desde que Jesús comenzó a reunir discípulos. Sin embargo, se ha prestado poca atención sistemática a su papel como promotores de la paz. La Biblia no ofrece una teología coherente de la paz, pero pasajes clave como la bendición de Jesús para los pacificadores (Mateo 5: 9) y su consejo de "volver la otra mejilla" -una iniciativa transformadoraproporcionan un marco para tal teología.

Pablo de Tarso vio las iglesias (ekklesiae), un término que significa las comunidades políticas, económicas y religiosas de los convertidos, como instrumentos en manos de Dios, para la transformación pacífica de un mundo reconciliado a través de la muerte y resurrección de Jesucristo. A lo largo de los milenios evolucionaron dos modelos básicos de consolidación de la paz; el pacifismo fue el enfoque de los primeros padres de la iglesia como Tertuliano, reemplazado por el modelo de guerra justa lanzado por Agustín y refinado por Tomás de Aquino, que establece pautas para los líderes políticos sobre el uso de la fuerza.

Lutero y Calvino apoyaron básicamente el enfoque católico, mientras que los reformadores radicales como Menno Simons insistieron en la aplicación literal del llamado de Jesús a la resistencia no violenta al conflicto armado. Un tercer enfoque - la Guerra santa - ganó el apoyo papal en las Cruzadas y todavía tiene ecos en el período actual, pero ha sido rechazado por la mayoría de los líderes cristianos responsables. Ninguno de los modelos básicos proporciona mucha orientación para los activistas cristianos por la paz.
En las últimas dos décadas, ha surgido un nuevo modelo, "Paz justa", para llenar esa brecha, basado en "iniciativas transformadoras" del Nuevo Testamento, aprovechando las lecciones aprendidas de la lucha contra la esclavitud, el colonialismo y el racismo y aplicando las ideas extraídas de las teologías de liberación centrada en los pobres, las mujeres y los pueblos indígenas. Paz justa apoya el activismo en nombre de la paz mediante la abogacía, la promoción del diálogo entre las partes en conflicto y la acción directa no violenta. El nuevo modelo puede ser utilizado tanto por pacifistas como por aquellos que creen que la fuerza armada a veces puede ser necesaria para hacer frente a un conflicto violento.

Palabras clave: modelo, cultura de paz, construcción de paz, paz justa, reformadores.

\section{Abstract}

Christians have been engaged in peacebuilding since Jesus began gathering disciples. However, little systematic attention has been given to their role as peacebuilders. The Bible does not offer a coherent theology of peace, but key passages such as Jesus' blessing for peacemakers (Matthew 5:9) and his counsel to "turn the other cheek" - a transforming initiative - provide a framework for such a theology. Paul of Tarsus viewed the churches (ekklesiae), a term signifying political, economic and religious communities of the converted, as the instruments in the hands of God, for the peaceful transformation of a world reconciled through the death and resurrection

* Embajador, consultor y conferenciante en la construcción de paz internacional. Predicador laico en la Iglesia Metodista Unida de los Estados Unidos. Graduado en la Universidad de Harvard. Doctorado en Relaciones Internacionales de la Escuela de Derecho y Diplomacia Fletcher. Estudios realizados en el Seminario teológico de Unión en Nueva York. 
of Jesus Christ. Over the millennia two basic models of peacebuilding evolved; pacifism was the approach of early church fathers like Tertullian, superseded by the just war model launched by Augustine and refined by Thomas Aquinas, which sets out guidelines for political leaders on the use of force.

Luther and Calvin basically endorsed the Catholic approach, while radical reformers like Menno Simons insisted on literal application of Jesus' call for nonviolent resistance to armed conflict. A third approach - Holy War - gained papal support in the Crusades and still has echoes in the current period, but has been rejected by most responsible Christian leaders. Neither of the basic models provides much guidance for Christian peace activists.
In the past two decades a new model - "Just Peacemaking" - has emerged to fill that gap, grounded on New Testament "transforming initiatives," drawing on lessons learned from the struggle against slavery, colonialism and racism and applying the insights drawn from theologies of liberation focused on the poor, women and indigenous peoples. Just Peacemaking supports peace activism through advocacy, promotion of dialogue between warring parties, and non-violent direct action. The new model can be used both by pacifists and those who believe that armed force may sometimes be necessary to deal with violent conflict.

Key words: Model, culture of peace, peacebuilding, just peamaking, reformers.
Durante más de dos milenios los cristianos han participado en la construcción de la paz. En muchos casos han actuado por compasión por los que están en conflicto o por una pasión por reparar las injusticias que causan o emergen del conflicto. Principalmente, han trabajado para restablecer un orden pacífico dentro de las iglesias. De vez en cuando los líderes cristianos se han encontrado en funciones de resolución de conflictos en sus comunidades más amplias y ocasionalmente a nivel nacional e internacional. Sin embargo, históricamente, los líderes y pensadores cristianos no han dedicado mucho tiempo a reflejar sistemáticamente sobre su papel como pacificadores. Eso puede ser una sorpresa para algunos, quienes apuntarán al ejemplo de valientes pacifistas o mencionarán la solemne doctrina sobre violencia y guerra declarada por la iglesia desde la época de Agustín de Hipona.

\section{Guía bíblica para promover una cultura de paz}

La palabra "paz" aparece frecuentemente en la Biblia más de 400 veces en el Antiguo y el Nuevo Testamento juntos. Muchas de estas referencias se refieren a un espíritu pacífico para los individuos, pero numerosos pasajes de la Biblia reflejan la esperanza de paz para las personas y las naciones. La Biblia no ofrece una teología coherente de la paz, pero hay pasajes clave que proporcionan un marco para tal teología. De hecho, para los cristianos, la Biblia es una fuente primaria para la construcción de la paz.
Esa declaración debe ser avanzada con precaución, porque la Biblia es ocasionalmente un libro de texto ambiguo. Algunos como el fallecido Christopher Hitchens han argumentado que el judaísmo y el cristianismo son intrínsecamente violentos porque surgen de textos llenos de violencia. ${ }^{1}$ Tales críticos citan Deuteronomio 7, que atribuye a Dios el mandato de cometer genocidio contra el pueblo de Canaán, y al libro de Apocalipsis en el Nuevo Testamento, que retrata la violencia catastrófica contra los enemigos de Dios y el Mesías de Dios. Y un dicho atribuido a Jesús complica su imagen de constructor de paz: "No penséis que he venido para traer paz a la tierra; no he venido para traer paz, sino espada "(Mateo 10: 34-35).

\section{A. La Biblia hebrea}

En el Antiguo Testamento, tres citas son particularmente dignas de mención:

- "Yo estaré contigo" (Génesis 31: 3). Esas palabras fueron las palabras de YHWH a Jacob, instrucciones para regresar con esposas e hijos a su tierra natal. Las palabras pusieron en movimiento su valeroso y exitoso esfuerzo por hacer la paz con su hermano guerrero Esaú. Esaú había jurado matar a Jacob después de vender su primogenitura a su hermano menor. Jacob preparó cuidadosamente para el encuentro y luego descubrió - para su gran alivio - que Esaú estaba dispuesto a perdonarlo. (El texto implica que Dios actuó para persuadir a Esaú de hacerlo). La misma promesa es repetida por el profeta

1 Christopher Hitchens, God is Not Great (2007) 
identificado por los eruditos como Segundo Isaías (Isaías 41:10): “No temas, porque yo estoy contigo. ... Yo soy tu Dios." ${ }^{2}$ Más adelante aparecerá en el Nuevo Testamento, en las últimas palabras de Jesús a sus discípulos antes de su arresto (Mateo 28:20): "Yo estoy con vosotros todos los días hasta el fin del mundo". Ésa es una consigna para los cristianos que participan en la construcción de la paz.

- "La justicia y la paz se besaron" (Salmo 85:10). Es improbable que la paz se sostenga a menos que se entienda que el acuerdo acordado proporciona justicia para los agraviados. En la Biblia hebrea la paz (shalom) y la justicia (tsadeq) están estrechamente vinculadas. La justicia debe ser un objetivo principal de la construcción religiosa de la paz.

“Y... [el Señor] juzgará entre las naciones, y reprenderá a muchos pueblos; y volverán sus espadas en rejas de arado y sus lanzas en hoces; no alzará espada nación contra nación, ni se adiestrarán más para la guerra." (Isaías 2: 4).

\section{B. El Nuevo Testamento}

En el Nuevo Testamento, los cristianos miran primero a las palabras de Jesús. Además de la bienaventuranza conferida a los pacificadores, Jesús ofrece en el Sermón de la Montaña un enfoque llamativo a la construcción de paz: "No resistan al que les haga mal. ... Si alguien te da bofetada en la mejilla derecha, vuélvele también la otra" (Mateo 5:38-Nueva versión internacional). No es un consejo de pasividad. El contexto de la observación de Jesús a menudo ha sido malinterpretado. El contexto es el de un poder físico asimétrico entre un grupo y otro. Jesús estaba hablando de un judío desarmado frente a un soldado romano. Además, como ha señalado el fallecido Walter Wink, Jesús no estaba hablando de una pelea de puño, sino de un revés en la cara. Una pelea de puño sería entre iguales, no era una opción digna para un soldado romano. Un revés con la mano derecha a través del lado derecho de la cara del judío era un insulto devastador. Wink llama al consejo de Jesús "una iniciativa transformadora". Girar la mejilla izquierda hacia el agresor le enfrentaría con una opción poco atractiva. ¿Debería utilizar su brazo izquierdo más débil para revés en la mejilla izquierda, o debería recurrir a sus puños, reconociendo así, implícitamente la igualdad de la persona agredida? ¿O podría el agresor ser movido a pensar de manera diferente sobre el enfrentamiento frente al valor y determinación de su víctima? ${ }^{3}$

En Mateo, Jesús también abordó los conflictos surgidos dentro de la comunidad de fe. "Si tu hermano peca contra ti, ve y repréndele estando tú y él solos. Si te oyere, has ganado a tu hermano. Mas si no te oyere, toma aún contigo a uno o dos para que en boca de dos o tres testigos conste toda palabra. Si no los oyere a ellos, dilo a la iglesia; y si no oyere a la iglesia, tenle por gentil y publicano"(18: 15-18). La referencia a la iglesia era probablemente una adición posterior a las palabras recogidas de Jesús, ya que no trató con una "iglesia" durante su ministerio, pero la fórmula de dos a tres testigos recapitula un enfoque establecido en Deuteronomio 19:15. Irónicamente, la última frase del v. 17, que prescribe el castigo para un "hermano" que aún no responde - exclusión de la asamblea como gentil y recaudador de impuestos - parece discordante con la propia comunión de Jesús con el publicano Levi y con algunos gentiles. La directriz para el diálogo individual con el delincuente y luego con 2-3 testigos

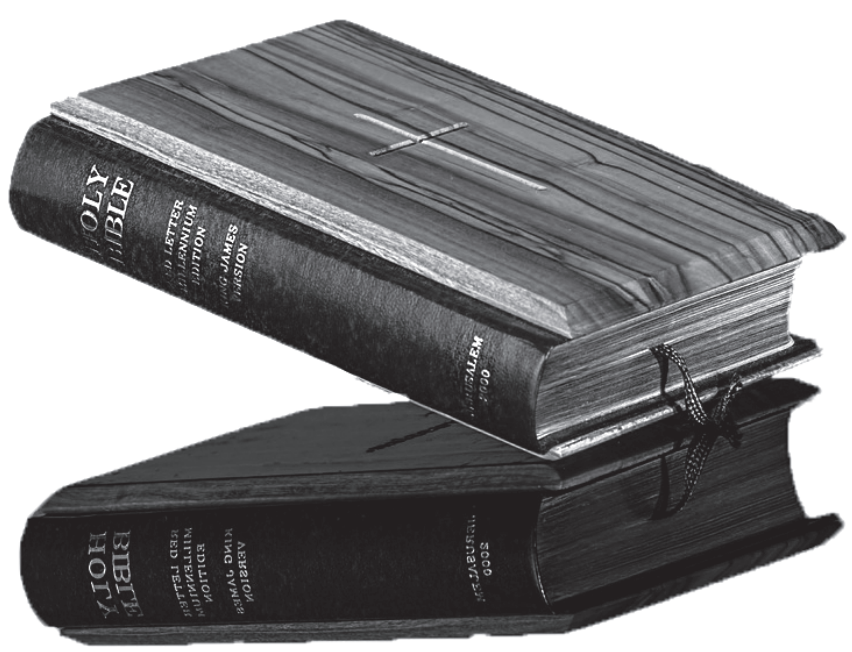

Pixabay.com

2 Para esta cita y la siguiente, véase John Paul Lederach, Reconcile: Conflict Transformation for Ordinary Christians(2014), $29-43,83-92$.

3 Walter Wink, Jesus and Nonviolence: A Third Way (2003), 9-16. En vv. 41 y 42 Jesús añade otras "iniciativas transformadoras". Dar una camiseta, así como ropa exterior significa estar desnudo, avergonzando al demandante. Ir a una segunda milla más allá de la milla requerida por la ley podría poner en problemas al soldado romano. $17-25$. 
sigue siendo un enfoque inicial válido para el conflicto dentro de la iglesia e intracomunidad.

En sus cartas, Pablo de Tarso demostró una preocupación primordial por forjar la armonía interna en las iglesias nacientes de Asia Menor y Grecia y por proyectar externamente amor y reconciliación a potenciales conversos gentiles.

¿Qué eran estas "iglesias" - estas comunidades de los convertidos? Pablo los llamó ekklesiae. Richard Horsley argumenta que las ekklesiae eran más que comunidades "religiosas". Él señala que ekklesia, traducida como "iglesia" en la mayoría de las versiones del Nuevo Testamento, era el mismo término usado para la "asamblea" de ciudadanos en la ciudad-estado griega. Así, ekklesia, un término que Pablo usó para el movimiento cristiano en general, así como para las comunidades individuales, era una comunidad política, así como religiosa. La ekklesia reclutaba de la sociedad imperial, pero evitaba en la medida de lo posible la participación en esa sociedad. El objetivo de la asamblea de Pablo era "constituir una comunidad alternativa a la de la sociedad imperial dominante" ${ }^{\prime 4}$. Los participantes en estas comunidades se esperaban que se amaran, se sirvieran unos a otros y compartieran sus posesiones materiales.

¿Qué tiene eso que ver con la paz? Para responder a esa pregunta debemos tratar de entender la visión más amplia de Pablo acerca del mundo que él creía que Dios estaba creando a través de la muerte $y$ resurrección de Jesús. Era una cosmovisión p r of und a m e n t e diferente a la que subyacía el culto religioso que los gobernantes
Imperio Romano estaban tratando de imponer. De hecho, era una visión alternativa de la paz mundial. Pablo utilizó deliberadamente términos compartidos por el culto imperial romano para ilustrar las visiones contrastantes. John Dominick Crosson ha presentado la comparación de la siguiente manera:

- El gobierno imperial romano retrató a César Augusto como un hijo de Dios. Pablo describe a Jesús como el hijo de Dios.

- Augusto proclamó la paz a través de la victoria militar general. Pablo, en cambio, interpretando a Jesús, predice la paz mundial mediante la justicia.

- Para Augusto, uno de los instrumentos de la paz mundial era una religión que promovía el culto de un emperador divino. Para Pablo, sin embargo, el instrumento para traer la paz al mundo fue Jesucristo, crucificado y resucitado, que actúa a través de la transformación de comunidades e individuos. En contraste con el emperador, Jesús vivió una vida de siervo- enseñando, sanando, protestando contra la injusticia y muriendo de acuerdo con su misión profética. ${ }^{5}$

Para Pablo, el instrumento humano -en las manos de Dios- de esta transformación pacífica fueron las ekklesiae, las comunidades políticas-económicasreligiosas de los convertidos. Y Pablo, al tratar el conflicto con "enemigos", recapituló la iniciativa transformadora atribuida a Jesús en Mateo 5.

El amor sea sin fingimiento. ... Bendecid a los que os persiguen; bendecid y no maldigáis. ... No paguéis a nadie mal por mal. ... No os venguéis vosotros mismos. ... Así que, si tu enemigo tuviere hambre, dale de comer; si tuviere sed, dale de beber; pues haciendo esto, ascuas de fuego amontonarás sobre su cabeza. (Romanos 12: 9-20).

4 Richard A. Horsley, ed., Paul and Empire: Religion and Power in Roman Imperial Society (1997), 8.

5 John Dominick Crosson, God and Empire: Jesus against Rome, then and now (2007), 10-28. Crosson descarta el consejo de Pablo de "someterse" a las autoridades, ordenadas por Dios (Romanos 13:1), como una advertencia para pagar impuestos. Véase el análisis de Aquino y Calvino a continuación. 


\section{Enfoques teológicos del conflicto y el uso de la fuerza}

Durante un periodo de dos milenios ha habido dos modelos básicos para la construcción cristiana de la paz: el pacifismo y la guerra justa. Ninguno de los dos ha proporcionado una estrategia para los activistas de la consolidación de la paz. Un tercer modelo, la guerra santa o cruzada, ha sido generalmente desacreditado.

\section{A.Pacifismo}

Los "padres" de la iglesia que operaban en los centros urbanos de Roma, Antioquía (Siria), Alejandría y Cartago (África del Norte), comenzaron ya en el siglo II a desarrollar conceptos teológicos y éticos que los cristianos todavía utilizan hoy en día. Entre ellos, Justino Mártir, Ireneo y Orígenes tenían ideas sobre la violencia. El más sistemático fue Tertuliano (160220). Hizo dos puntos básicos con respecto al servicio militar:

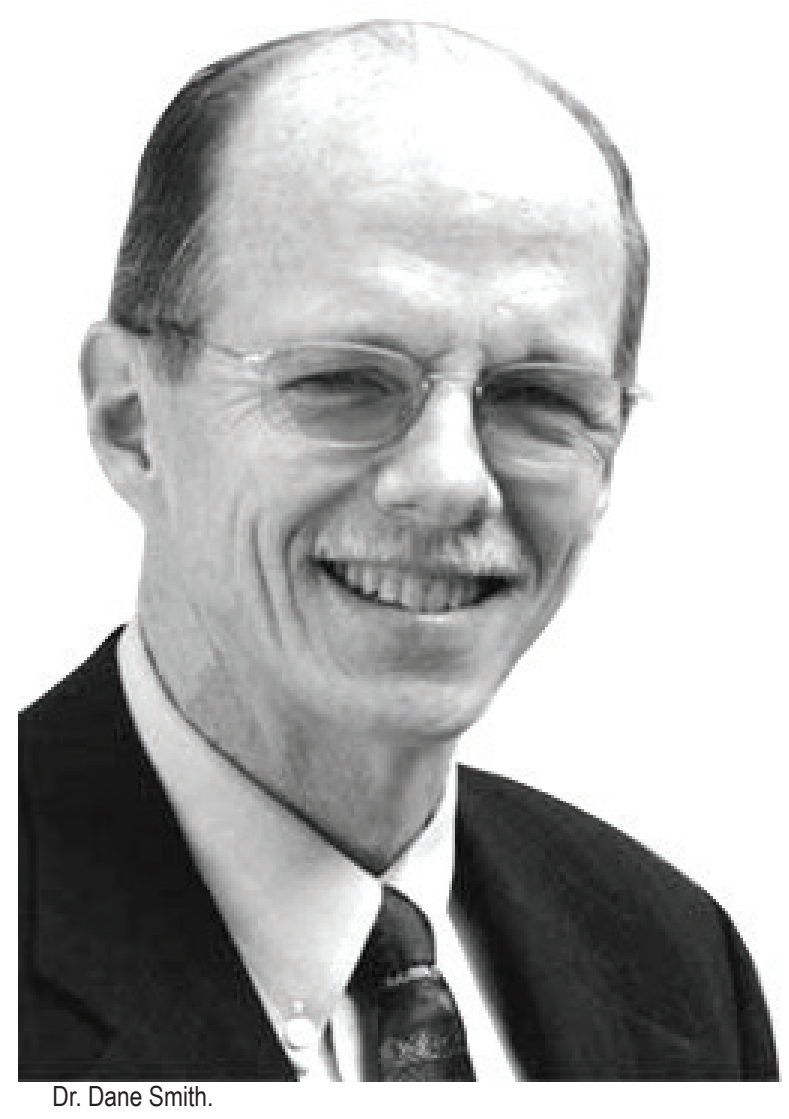

- Israel fue justificado en la guerra, pero Jesús anunció la llegada de un nuevo reino: las espadas se transformarían en arados y las disposiciones feroces se hicieron pacíficas. Así, el mandamiento de la no violencia en el Sermón de la Montaña es una prohibición literal. El mandamiento del amor se amplía para incluir extraños y enemigos.

- Los que experimentan violencia no deben tomar represalias dela misma manera. Pueden consolarse con la venganza eventual de Dios. También pueden tomar gratificación en "la decepción y la confusión del agresor ante la pasividad firme". Ese consejo evoca la interpretación de Wink de la "iniciativa transformadora" de Jesús en "dar la otra mejilla". Los cristianos podrían usar el humor y el ridículo para compensar su desventaja de poder.

Tertuliano dudaba que un cristiano fiel pudiera ocupar un cargo gubernamental, porque se esperaría el apoyo a los templos, los sacrificios a los dioses y la atribución de cualidades divinas a la línea imperial, así como la participación en torturas y encarcelamiento bajo el sistema de justicia. El servicio militar implicaba incluso, una mayor tentación hacia el mal comportamiento, incluida la participación activa o pasiva en el homicidio. Además, el uso del uniforme, con su símbolo de la corona, implicaba primordial lealtad al Estado en lugar de a Jesucristo. ${ }^{6}$

Estos padres de la iglesia eran pacifistas. Pero, ellos no tenían un programa de construcción de paz. No ofrecieron ideas para domar la violencia de la vida política ni para lograr la paz donde había guerra.

Este pacifismo temprano se desvaneció cuando el Imperio Romano se hizo cristiano. No fue revivido hasta que los anabaptistas aparecieron en la Reforma. Los anabaptistas, que inicialmente incluían a los hermanos suizos, menonitas y hutteritas, fueron los más radicales de los reformadores en su insistencia en la Biblia como base para la vida en la fe (sola scriptura). Ellos buscaron un retorno a la iglesia "primitiva" del primer siglo. Insistieron en que la enseñanza de Jesús en el Sermón de la Montaña era el modelo básico de la vida.

El principal teólogo anabaptista fue el holandés Menno Simons (1495-1561). Él consideraba la Biblia

6 De Corona. Véase Lisa Cahill, Love Your Enemies: Discipleship, Pacifism and Just War Theory (1994), 41-48. 
como la palabra de Dios, pero argumentaba que el Antiguo

Testamento debía ser leído a través de la lente de Jesucristo.

El Nuevo Testamento tuvo precedencia.

$\mathrm{T}$ e $\mathrm{r} \mathrm{t} \mathrm{u} \mathrm{l}$ i a $\mathrm{n}$ o considerabaquelas palabras de Jesús debían tomarse con la máxima seriedad. Menno exhortó a los anabaptistas a no resistir a los perseguidores. De hecho, durante ese período temprano, los menonitas vivieron con la expectativa del martirio - identificándose con Jesús en su muerte. Estaban convencidos de que la persecución no cesaría mientras tanto los justos como los injustos vivían juntos en la tierra. Esperaban el regreso de Cristo para traer a los santos a su recompensa. ${ }^{7}$

En el siglo XVII surgieron los Cuáqueros - la Sociedad Religiosa de Amigos. Su principal teólogo fue George Fox (1624-1691). Fox y los cuáqueros rechazaron las guerras del Antiguo Testamento como contrarias a la nueva ley de Jesús y, por tanto, incompatibles con el mensaje básico del evangelio: el arrepentimiento, la misericordia, la paz y la no resistencia.

Hoy en día las "iglesias de la paz" - ahora principalmente los menonitas, los cuáqueros, la Iglesia de los Hermanos, los Cristadelfianos y los Adventistas del Séptimo Día - continúan oponiéndose a la guerra y al servicio militar. En el pasado sus miembros fueron castigados a menudo por negarse a prestar servicio militar al estado. El derecho a la "objeción de conciencia" fue reconocido en muchos países, hasta en el siglo XX.

\section{B. La guerra justa}

Agustín de Hipona (354-430), un gigante del pensamiento occidental, desarrolló un marco comprensivo para entender la relación entre la iglesia y la autoridad estatal. En su obra maestra, La Ciudad

El actor es una autoridad legítima;

2. el objetivo es castigar el crimen o mantener la paz;

7 Cahill, 163-165, 176 
3. el objetivo final es restaurar la justicia, no castigar al enemigo.

Esas condiciones deberían regir tanto el poder policial del gobierno como su capacidad para emprender una guerra contra otra entidad política. ${ }^{8}$

Agustín dijo que los seres humanos como individuos no están autorizados a usar la violencia, ni siquiera en defensa propia contra los criminales. La violencia es legítima sólo como una función estatal utilizada para mantener el orden social. La policía y los soldados pueden usar la fuerza sólo como representantes del soberano, no como individuos.

Ocho siglos más tarde Tomás de Aquino, maestro teólogo de la Iglesia Católica, examinó la cuestión en su Summa Theologica. Tomás tomó en cuenta las palabras de Jesús acerca de no resistir el mal y su afirmación de que "todos los que toman la espada perecerán por la espada". Sin embargo, concluyó que ya que Jesús le dijo a los soldados que se contentaran con su salario (Lucas 3:14), no estaba prohibiendo una carrera militar.

Sus conclusiones se elaboraron sobre las de Agustín:

- "Una guerra justa" debe ser librada por un soberano y por aquellos a quienes delega el uso de la fuerza.

- La guerra debe tener una causa justa, rectificar las quejas o restaurar lo que ha sido injustamente tomado.

- La guerra debe tener la intención correcta. No puede librarse de la crueldad o aumentar el territorio o el poder real, sino más bien para garantizar la paz, castigar a los malhechores o adelantar la bondad. ${ }^{9}$

En otra parte, agregó como "defensa correcta" la defensa de la seguridad pública, la defensa del culto cristiano, y - poco notado entonces y después - la protección de los pobres y oprimidos.

Aquino examinó si un gobernante podía ser considerado una "autoridad gobernante" dentro del alcance de Romanos 13:1-7. Él concluyó que no todos los gobernantes derivan su poder de Dios, particularmente si aseguran sus posiciones por la violencia o el soborno. En tales casos, "es permisible rechazar tal autoridad". Dicha autoridad puede legitimarse posteriormente si es avalada por una autoridad superior en la cadena de mando o por el consentimiento popular. ${ }^{10}$ No aclaró si el rechazo podría tomar la forma de una resistencia no violenta o violenta.

Los principales reformadores, Martín Lutero (14831546) y Juan Calvino (1509-1564), aunque severamente críticos de la teología católica, siguieron a Agustín y Tomás de Aquino sobre el uso de la fuerza. Según Lutero, en la medida de lo posible, el cristiano debe amar a los vecinos y enemigos y evitar el recurso a la violencia en favor de la no resistencia. Al igual que Agustín, Lutero se preocupaba por la anarquía. La guerra sólo debe ser emprendida por la autoridad legítima. Denunció la revuelta campesina de 15241525 contra los príncipes alemanes, aunque creía que el campesinado tenía graves quejas. No tenían autoridad legítima para hacer la guerra contra sus gobernantes. Lutero puso mucho énfasis en la "sumisión a las autoridades superiores" (Romanos 13: 1). El propósito de la guerra debe ser el restablecimiento de la paz y la justicia y la defensa de la nación. Ser un soldado bajo autoridad debidamente constituida es legítimo. Así Tomás de Aquino, se opuso a las guerras religiosas como las libradas contra los turcos otomanos. ${ }^{11}$

En la opinión de Calvino, la comunidad espiritual necesitaba el apoyo de la comunidad civil para mantener su coherencia. Por lo tanto, aunque la autoridad civil estaba impregnada por el pecado, aseguró el orden público, la paz y la tranquilidad, y proporcionó reparación legal. Calvino estuvo de acuerdo con Lutero y Agustín en que la autoridad política viene de Dios y debe ser respetada y obedecida. La autoridad legítima del Estado incluye la función policial y la resistencia militar a la agresión externa. Sin embargo, no es incondicional; un rey actuando contra Dios debe ser resistido, una posición similar a la de Aquino. ${ }^{12}$

8 La Ciudad de Dios, Libro 19, particularmente Capitulo 12. Véase Cahill, 71, y más generalmente 55-80.

9 Tomás de Aquino, Summa Theologica, Parte II-2, Pregunta 40, "Sobre la Guerra."

10 Summa, II-2, Pregunta 188,3; Comentario a las sentencias de Pedro Lombardo, Libro 2, Distinción 44, Preg. 2

11 Lutero, Sobre la Autoridad Temporal, 96,100, 87; Sobre la Guerra contra los Turcos.

12 Calvino, Institución de la religión cristiana, 4:20:30-32. Véase también sobre Lutero y Calvino, Cahill 101-116.

Maria J. Stephan, "What Happens When You Substitute Just Peace for Just War?", Foreign Policy, 18 de mayo de 2016, http://foreignpolicy.com/2016/05/18/ pope- francis-just-peace-catholic-vatican-africa-isis/. 


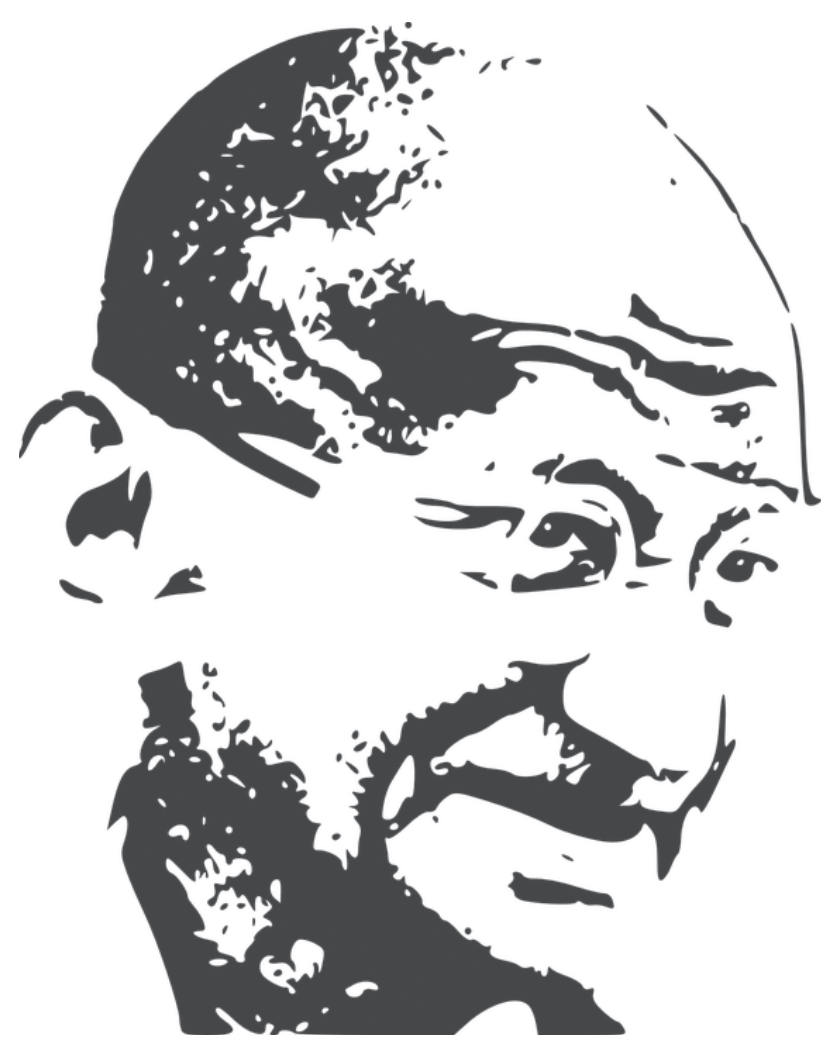

La guerra justa ha permanecido como una doctrina católica oficial, en los últimos años consagrada en el Catecismo de 1992 de la Iglesia Católica. Sin embargo, una conferencia de 2016 sobre "La no violencia y la paz justa", patrocinada en parte por El Vaticano, recibió una carta del Papa Francisco dando la bienvenida a sus "pensamientos sobre la revitalización de las herramientas de la no violencia", señalando así un posible alejamiento de la guerra justa. ${ }^{13}$

\section{Santa Guerra o Cruzada}

Hay un tercer modelo: guerra santa o cruzada. Aunque en gran parte desacreditado por los pensadores cristianos, el modelo de la cruzada se ha continuado de vez en cuando, a manera de reacciones populares.

En 1095 el Papa Urbano recibió una solicitud de ayuda del emperador bizantino, porque los turcos seljúcidas amenazaron a Constantinopla, la sede de la Iglesia Ortodoxa Oriental. Los turcos ya habían expulsadoalos bizantinos del resto de la actual Turquía. Urbano tenía una idea más grande: no sólo para salvar a Bizancio, sino para recuperar Jerusalén de los musulmanes, que la habían conquistado 300 años antes. En una gira por Francia, declaró a las multitudes que el lugar de enterramiento tradicional de Jesús, la Iglesia del Santo Sepulcro, estaba en manos de los musulmanes, "una raza totalmente ajena a Dios". Exhortó a los cristianos a abandonar su hogar y su familia, levantar la cruz de Cristo y reconquistar Jerusalén. Los que iban, el Papa prometió, recibirían el perdón de sus pecados. Irían directamente al cielo si morían en cruzada. Unas 130.000 personas respondieron, entre ellas mujeres y niños. Los cruzados se tomaron Jerusalén y establecieron un reino que duró cerca de 90 años, antes de que el general musulmán Salah Ad-Din (Saladino) retomara la ciudad. Los piadosos cruzados pasaron a muchos musulmanes y judíos por la espada en la conquista de Jerusalén. Salah Ad-Din, en cambio, salvó a civiles cristianos y judíos cuando triunfó.

Lo más llamativo en el modelo original de la guerra santa es que sus defensores argumentaron que el amor cristiano y el discipulado no se aplicaban a los seguidores de otras religiones. No sólo se justificaba la hostilidad hacia ellos; era permisible aniquilarlos. ${ }^{14}$

Este modelo ha sido despreciado y abandonado por la mayoría de los cristianos. A pesar de que Tomás de Aquino y Lutero -y las iglesias católicas y protestantes - rechazaron la legitimidad de la guerra contra otras religiones, este modelo sigue influyendo en algunos que están llenos de temor y odio hacia otras religiones. Hoy en día, en algunos países occidentales, ciertos políticos han afirmado que, a causa de los ataques de 2001 contra el Centro Mundial de Comercio en Nueva York y de numerosos asesinatos terroristas de civiles en nombre del islam, Estados Unidos y el mundo occidental están "en guerra" con el islam . Estas declaraciones hasta ahora han sido evitadas por líderes políticos responsables que han insistido en que, aunque la acción militar puede justificarse para detener la violencia terrorista islámica, la ideología terrorista no representa las opiniones de la gran mayoría de los musulmanes del mundo. ${ }^{15}$

13 Maria J. Stephan, "What Happens When You Substitute Just Peace for Just War?", Foreign Policy, 18 de mayo de 2016, http://foreignpolicy.com/2016/05/18/ popefrancis-just-peace-catholic-vatican-africa-isis/

14 Cahill, 122

15 Algunos alegan que tales opiniones están representadas en la Administración Trump. En el momento de redactar el presente informe, no se han hecho declaraciones oficiales sobre una guerra contra el Islam. 


\section{La lucha por la liberación: lecciones aprendidas en los siglos XIX y XX}

En los últimos dos siglos, los temas de la violencia y la paz a menudo se entrelazaron con el tema de la liberación.

\section{A. La lucha contra la esclavitud}

La transferencia forzada de africanos al Hemisferio Occidental como mano de obra esclava aportó un impulso importante al rápido crecimiento económico de Europa y Estados Unidos, que condujo a la expansión del poder y la influencia global occidental en el siglo XIX. Sin embargo, a principios de ese siglo, la oposición a la esclavitud ganó fuerza. El cristiano evangélico William Wilberforce dirigió la campaña en el Parlamento británico que aprobó una ley para abolir el comercio de esclavos en 1807, que a su vez llevó al fin de la esclavitud en el Imperio Británico en 1833.

Una generación más tarde, Henry David Thoreau, buscando la verdad de la revelación personal de Dios a través de la contemplación privada, comenzó lo que él llamó "vida sencilla" en una casa de campo aislada. Cuando fue abordado por un recaudador de impuestos, se negó a pagar, diciendo que no iba a proporcionar ingresos al gobierno federal para apoyar la esclavitud en los Estados Unidos. ${ }^{16}$ Fue encarcelado hasta que un miembro de la familia pagó el impuesto. Luego escribió un famoso ensayo, "La Desobediencia civil". Él sostuvo que la conciencia era una autoridad superior a la ley, y por lo tanto, cuando la conciencia encontró una ley inmoral, el individuo tenía un deber de la desobediencia civil. Tal acción y su castigo podrían despertar la conciencia de otros ciudadanos para pedir el cambio. No basó su argumento en la teología cristiana. El enfoque de Thoreau era altamente individualista. Sin embargo, sus ideas tuvieron gran influencia en el pensamiento futuro -tanto religioso como no religioso- acerca de la resistencia "no violenta".

Otras acciones no violentas para abolir la esclavitud en Estados Unidos incluyeron boicots de productos de la economía esclavista y el "ferrocarril subterráneo", una red de blancos y negros que viajaron hacia el sur para ayudar esclavos fugitivos en violación de la ley federal y establecer refugios para ellos en el norte. El activismo social en la iglesia protestante en los Estados Unidos ganó impulso en la lucha contra la esclavitud. Sin embargo, la no violencia no resolvió el problema en los Estados Unidos. En cambio, la guerra civil (1861-1865), que mató más que cualquier otro conflicto en la historia de Estados Unidos, terminó con la esclavitud.

\section{B. Liberación de los excesos del capitalismo: el evangelio social}

Walter Rauschenbusch (1861-1918), un pastor en los barrios bajos de la ciudad de Nueva York, se convirtió en el principal teólogo del evangelio social. Pidió una cuidadosa relectura de la Biblia y la aplicación de sus enseñanzas a los pobres y oprimidos de la era moderna. En A Theology of the Social Gospel (Teología del Evangelio Social) (1917), Rauschenbusch afirmó que el "Reino de Dios" era el mensaje fundamental de Jesús. Rechazó la noción de que el aspecto religioso de la vida podría separarse de lo político y lo social. El Reino de Dios tenía como objetivo no sólo "llevar a los individuos al cielo, sino... transformar la vida en la tierra en la armonía de los cielos". Él vio a las iglesias comprometidas con el Reino como vehículos para esta transformación, una interpretación en cierto modo cercana a la de Pablo, pero puso mucho más énfasis en la voluntad y determinación humanas que en la acción divina.

La transformación buscada por los proponentes del evangelio social se centró en los problemas sociales creados por la revolución industrial. Millones de trabajadores estaban luchando para ganarse la vida. Trabajaron largas horas en situaciones insalubres y a menudo peligrosas. Sufrían la falta de oportunidades educativas, mala salud y miseria en los barrios pobres de la ciudad. Estos problemas provocaron la violencia doméstica en las familias que viven en la pobreza. Generaron violencia laboral cuando los trabajadores reaccionaron contra los empleadores debido a los bajos salarios ya las malas condiciones de trabajo. Los defensores del evangelio social querían liberar a los trabajadores y sus familias de estas condiciones. Trabajaron para ampliar los derechos de

16 Thoreau también basó su rechazo a pagar en lo que él consideró una "injusta" guerra de los EEUU con México. 
los trabajadores y para mejorar la educación, la salud y el saneamiento urbano.

\section{Reinhold Niebuhr y el correctivo del realismo}

El teólogo protestante norteamericano Reinhold Niebuhr comenzó como un pastor en Detroit, el centro de la industria automotriz. Niebuhr simpatizaba con los objetivos del evangelio social, pero consideraba a Rauschenbusch ingenuo acerca de la relación entre el mal y el egoísmo humano. Niebuhr interpretó la historia de la caída de Adán y Eva en Génesis 2, como señalando el radical quebrantamiento de la humanidad. ${ }^{17}$ Los seres humanos no tienen la capacidad, según él, de trascender el egoísmo y la lujuria por el poder sin la gracia divina. Consideraba la lucha por la justicia en los ámbitos económico y social como esencial, pero difícil. El choque de intereses políticos individuales e institucionales, arraigados en el egoísmo humano, significaba que lograr la justicia requería lucha política - así como la gracia divina, no simplemente la buena voluntad y la determinación de los fieles cristianos.

Niebuhr aplicó este análisis, que se conoció como "realismo", a cuestiones de guerra y paz. Niebuhr comenzó su carrera como pacifista y criticó el modelo de la guerra justa. Señaló que cada líder insiste en que actúa con justa causa y con intención correcta, incluso cuando su acción constituye una agresión. Niebuhr argumentó que la teoría de la guerra justa suponía que era posible discernir la diferencia clara entre "justicia" e "injusticia" y entre "defensa" y "agresión". Ese análisis debe realizarse, pero con el reconocimiento de que tales juicios están influenciados por pasiones e intereses.

Por lo tanto, ninguna guerra podría cumplir el estándar de ser completamente justa. Sin embargo, a veces es necesario recurrir a la violencia para preservar valores importantes de la civilización como la democracia. ${ }^{18}$ Por lo tanto, apoyó la entrada de Estados Unidos en la Segunda Guerra Mundial como esencial para proteger la democracia y la religión del fascismo internacional. La teología de paz de Niebuhr proporcionó un correctivo a la confianza en la posibilidad de delinear criterios claros e inequívocos para las decisiones sobre la guerra. Él planteó preguntas adicionales para los tomadores de decisiones que de hecho se han incorporado a la doctrina católica de la guerra justa:

- ¿Cuáles son las alternativas? ¿Se han explorado otros enfoques y se ha considerado poco práctico?

- ¿Cuáles son los costos y beneficios? ¿Cuáles son las posibilidades de éxito? ¿Serán los resultados peores que la situación actual? ${ }^{19}$

\section{El final formal del colonialismo}

El fin del colonialismo marcó un tremendo cambio en las relaciones internacionales y dio esperanza a cientos de millones de pobres y oprimidos. La destrucción y el enorme costo de la Segunda Guerra Mundial hicieron imposible que continuaran los imperios coloniales en Asia, Oriente Medio y África. (El colonialismo terminó en gran parte por 1825 en las Américas, excepto para el Caribe). Aunque algunos países habían ganado la independencia antes de la guerra, la India abrió el camino en 1947 a una transición pacífica a la soberanía política. Para ese éxito, gran crédito se debe a Mahatma Gandhi. El hindú Gandhi, utilizando los conceptos de no violencia de Jesús y Henry David Thoreau, movilizó a millones efectivamente para exigir la independencia. Aparte de algunos teólogos sudafricanos, el proceso de descolonización en África y Asia recibió relativamente poca atención sistemática de los teólogos cristianos.

La experiencia de la India estableció el modelo utilizado por Gran Bretaña en el resto de Asia, Oriente Medio y África. Francia siguió el mismo modelo en el África subsahariana, después de que su resistencia a la independencia llevó a una terrible violencia en Indochina y Argelia. Por supuesto, otros pueblos coloniales como los del sur de África y los de la Unión Soviética no lograron su liberación hasta más tarde, pero la descolonización formal se completó en gran parte a principios de los años sesenta .Ciertos efectos políticos y económicos del colonialismo, por supuesto, han continuado mucho después de la independencia.

17 Reinhold Niebuhr, The Nature and Destiny of Man (1943), I:179-180

18 Niebuhr, Christianity and Power Politics (1940), 167-175-

19 Catecismo de la Iglesia Católica, 1992, http://www.vatican.va/archive/catechism_sp/index_sp/html. 


\section{E. Martin Luther King, la iglesia negra y la liberación de la discriminación racial sancionada por la ley}

Martin Luther King, Jr. lideró un movimiento que movilizó a la iglesia negra del sur de Estados Unidos alrededor de la promesa bíblica de liberación. King, un pastor con un doctorado en teología, se inspiró en una variedad de fuentes: en sus antepasados, en el movimiento abolicionista, el compromiso del evangelio social con los pobres y oprimidos y el realismo de Niebuhr sobre la complejidad del cambio social. También aprendió de las tácticas no violentas desarrolladas por Thoreau y Gandhi. Pero la influencia más importante en Martin Luther King Jr. -y la base de su éxito- fue la iglesia negra.

El culto negro en los Estados Unidos tiende a ser dinámico y centrado en la experiencia. Los fieles buscan conocer a Dios personalmente y discernir las revelaciones de Dios en sus vidas personales y corporativas. Siempre se han centrado en el significado de las narrativas bíblicas para sus comunidades. Las narraciones más importantes fueron la liberación judía de la esclavitud en Egipto, las denuncias de injusticia por parte de los profetas, y la misión, muerte y resurrección de Jesucristo. El mensaje central de los evangelios: Jesús vino a predicar la liberación de los pobres y oprimidos. Al morir en la cruz, Jesús tomó sobre sí el sufrimiento de los oprimidos.

En la resurrección Dios confirmó el triunfo de Cristo sobre los poderes de la muerte y la opresión. El significado de la resurrección y la continua presencia de Jesucristo se confirmaron en la predicación, los himnos y la experiencia general de adoración. Esa experiencia convenció a los cristianos negros de que alcanzarían la liberación al final, porque Dios los liberaría..$^{20}$ La experiencia de culto negro preparó a sus participantes para movilizarse en gran número detrás de sus pastores en nombre del cambio social. El presidente Lyndon Johnson aprovechó el éxito del movimiento dirigido por King para ganar la aprobación de leyes importantes en 1964 y 1965, que aseguraron que los negros tuvieran el derecho de votar y acabaran con la discriminación legal en el empleo y los servicios. Sin embargo, no terminó completamente

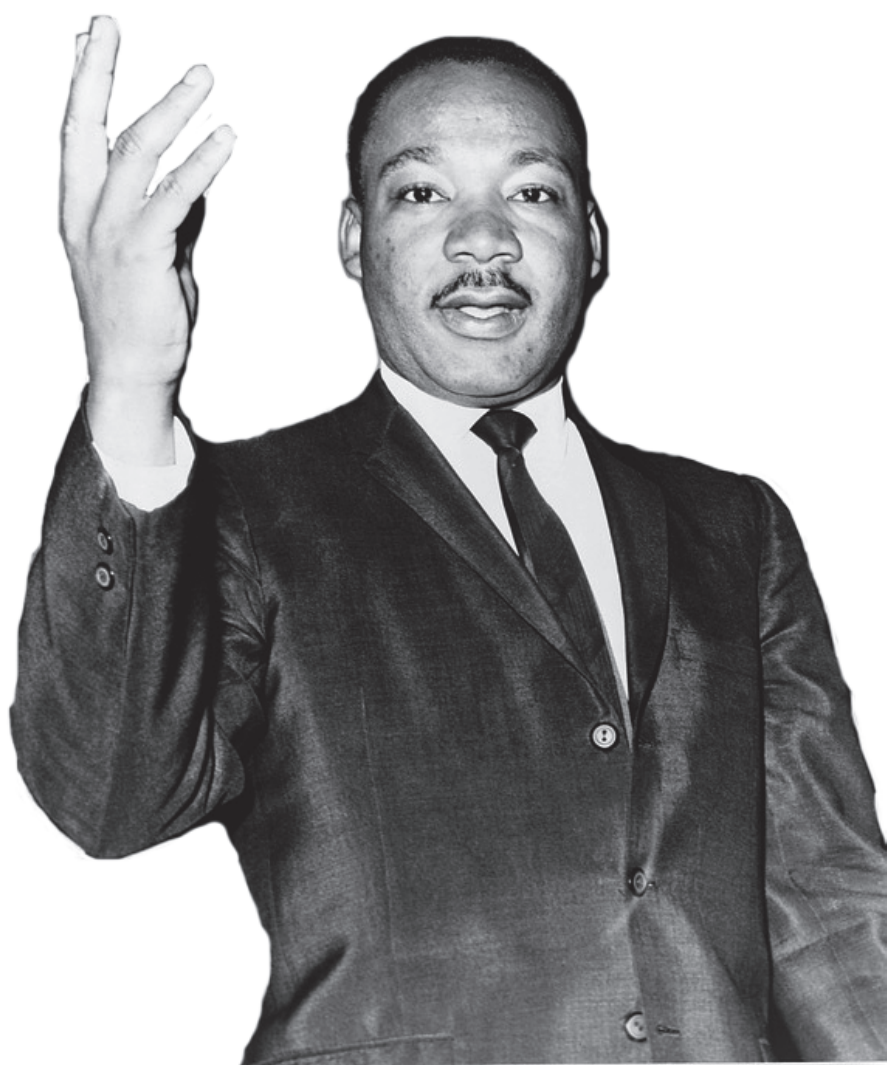

el racismo ni las prácticas y patrones informales de discriminación.

\section{F. Gustavo Gutiérrez: Teología de la Liberación}

En 1963, el Papa Juan XXIII publicó la encíclica Pacem in Terris. Afirmó que los ciudadanos tienen derecho a elegir a sus gobernantes y ser protegidos por una carta de derechos humanos fundamentales. Instó a los cristianos a "tomar parte activa en la vida pública". Juan convocó al Concilio Vaticano II para promulgar reformas de la iglesia. Su encíclica y el Consejo alentaron a un grupo de sacerdotes y obispos latinoamericanos críticos con la identificación de la iglesia con las clases dominantes. Ese grupo, que incluía al peruano Gustavo Gutiérrez y los brasileños Leonardo y Clódovis Boff, estaban preocupados por la situación de las masas pobres, en su mayoría mestizas. En 1971, Gutiérrez publicó su Teología de la Liberación.

20 James Cone, God of the Oppressed (1975), 108-137. R. Clifford Jones, "African-American worship," https://Jwww.ministrymagazine.org/archive/2002/09/africanamerican-worship-its-heritage-character-and-quality.html 
Gutiérrez sostuvo que la historia humana, bajo la soberanía de Dios, era una lucha continua por la libertad. Él llamó a Jesucristo "el Libertador". Pidió a la iglesia que pastoree a los oprimidos en su lucha de clases, denuncie esa opresión y proclame la presencia de Dios en el proceso de liberación. Instó a una alianza entre fuerzas religiosas y seculares para producir una utopía vagamente socialista para completar el proceso de liberación.

El Vaticano criticó el libro por su análisis marxista y lo acusó de dividir al "pueblo de Dios" de la jerarquía eclesiástica. La teología de la liberación perdió algo de su atracción internacional, pero siguió viva en América Latina, especialmente por el martirio de Monseñor Oscar Romero en El Salvador en 1980. Romero no era un discípulo de Gutiérrez sino fuertemente de lado de los pobres durante la cruel guerra civil de El Salvador. Los teólogos protestantes también han participado activamente en el debate sobre la liberación. El brasileño Rubem Alves (¿Religión: Opio del pueblo o instrumento de liberación? - 1969), el argentino José Míguez Bonino (Fe en búsqueda de efectividad -1967) y el cubano Sergio Arce Martínez han hecho importantes contribuciones.

\section{G. La Liberación de la mujer}

El movimiento que surgió a finales de los años sesenta y setenta, que pedía el fin de la discriminación contra la mujer en el lugar de trabajo, la educación y la política, no estaba dirigido por los cristianos. Los portavoces del movimiento a menudo criticaban a la iglesia por apoyar o condonar el patriarcado. Sin embargo, las mujeres que se identificaban como cristianas pronto comenzaron a criticar algunos de los supuestos tradicionales de teología y estudios bíblicos. Algunos reinterpretaron la Biblia para resaltar pasajes donde surge una visión diferente de las mujeres. Ejemplos, incluyen mujeres hebreas en Egipto que protegieron a los bebés judíos contra el esfuerzo genocida del Faraón (Éxodo 1: 15-22), la singularidad de las relaciones de Jesús con las mujeres y las mujeres como discípulas de Jesús y co-creadores con Pablo, de las nuevas iglesias gentiles. Una piedra de toque ha sido el pasaje de Gálatas 3:28: "Ya no hay judío ni griego, no hay esclavo ni libre, no hay varón ni mujer, porque todos vosotros sois uno en Cristo Jesús".
Esta reinterpretación ayudó a movilizar a muchas iglesias protestantes hacia el uso de un lenguaje neutro de género en la adoración, en la ordenación de las mujeres y en su proliferación como estudiantes y profesores en los seminarios protestantes. También condujo a la aparición de teologías feministas y "womanistas". En los Estados Unidos, Phyllis Trible exploró las imágenes femeninas de Dios en la Biblia, particularmente en Isaías 42:11-12 y 49:15, que usa metáforas que representan a Dios en el trabajo de parto o que cuidan a un niño.

Elizabeth Schussler Fiorenza, basándose en las cartas de autoría Paulina indiscutible, concluyó que Pablo veía a las mujeres como iguales en las iglesias, tanto como personas como colaboradoras cercanas en el ministerio. En México Elsa Tamez elucidó con perspicacia la historia de Agar, rechazada por Sara y Abraham, pero bendecida por Dios con el hijo de Abraham, Ismael, quien se convierte en el progenitor de la línea abrahámica abrazando árabes y musulmanes. La teología escrita por mujeres negras se ha convertido en un campo aparte: la teología "womanista." El argumento es que las mujeres negras son más oprimidas y necesitan ser más liberadas que las mujeres blancas y los hombres negros, porque tienen que lidiar simultáneamente con el racismo, el patriarcado y el clasismo. ${ }^{21}$

\section{H. Teologías indígenas de liberación}

Tanto en América Latina como en América del Norte, los grupos políticos blancos dominantes trataron de imponer el cristianismo a una población indígena diversa. Las religiones indígenas tendían a compartir una apreciación de la creación, de la tierra y de los lugares sagrados. En América Latina los españoles estaban comprometidos con la conversión de los nativos al cristianismo y se apresuraron a purgar prácticas culturales nativas que percibían como perjudiciales para ese objetivo. En América del Norte, fuera del suroeste español, el proceso comenzó dos siglos más tarde y fue más gradual, pero la política oficial también fue "resolver el problema indio" mediante la conversión de los pueblos indígenas al cristianismo practicado por personas de ascendencia europea. En ambas regiones muchas prácticas indígenas continuaron y hubo mucho sincretismo

21 Delores S. Williams ha escrito, "[En Agar] Dios encuentra a las mujeres afroamericanas en sus graves dificultades y las ayuda en su supervivencia diaria", Sisters in the Wildemess(1993), Capitulo 1 


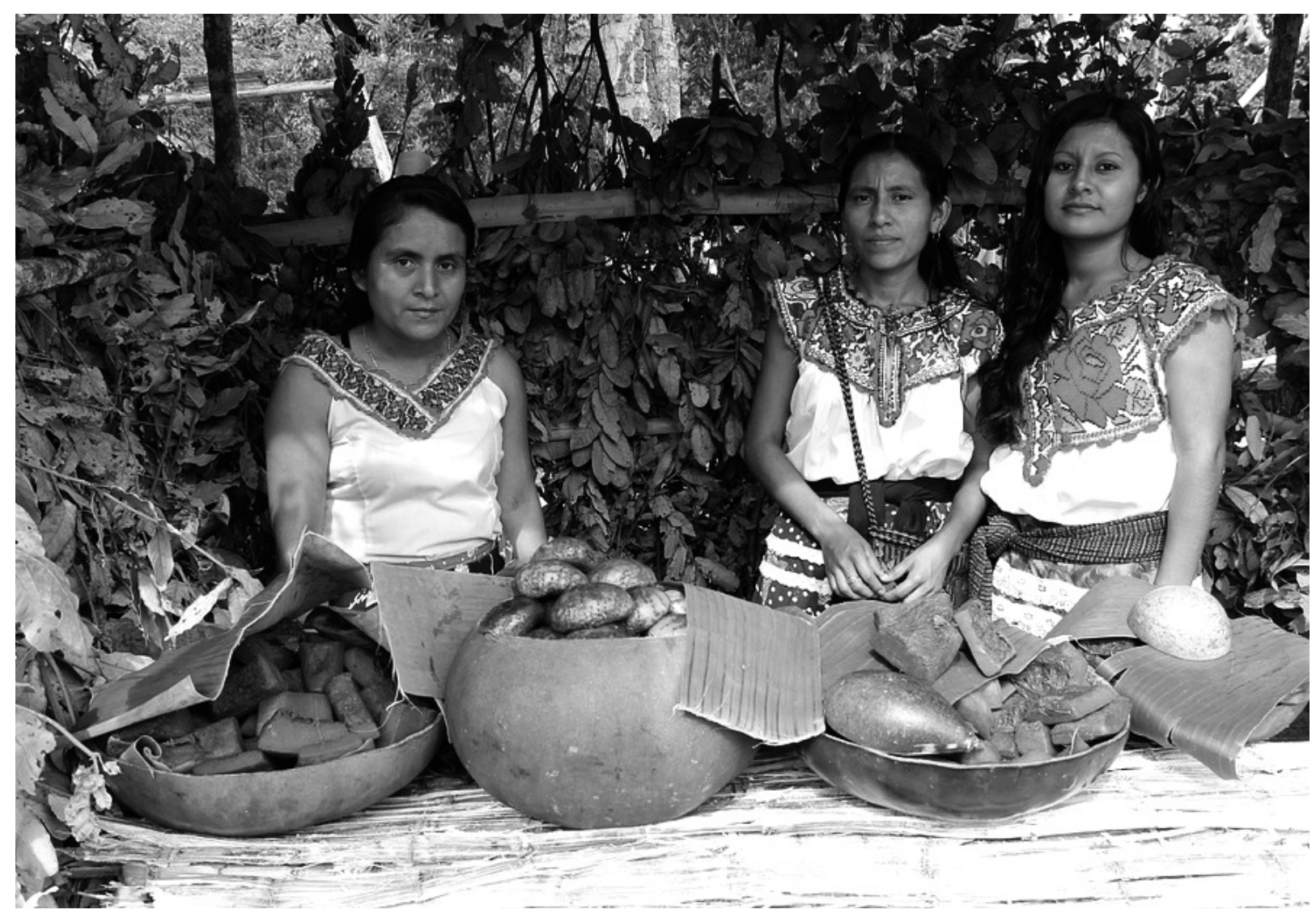

- la fusión de tradiciones occidentales e indígenas. En ambos lugares se realizaron grandes crueldades sobre los pueblos indígenas, en particular los niños y los jóvenes. En los siglos XVIII y XIX en las escuelas misioneras católicas de América Latina y en los internados protestantes de los Estados Unidos, los niños fueron aislados de sus familias y castigados por hablar su propia lengua y por seguir prácticas religiosas nativas. Sin embargo, la gran mayoría de los indígenas en ambos lugares se hizo cristiana.

En las últimas décadas ha surgido en el hemisferio occidental una vena rica, pero poco conocida, de reflexión teológica sobre la experiencia indígena. El teólogo George E. Tinker, miembro de la nación Osage y pastor luterano, enfatiza que la espiritualidad cristiana nativa americana se basa en la relación sagrada entre el pueblo y la tierra, una "teología del lugar".
Tinker ha desafiado directamente a la teología de la liberación en dos puntos principales:

- La teología occidental, incluida la de Gutiérrez, pone gran énfasis en la obra de Dios en la historia. Sin embargo, para los pueblos nativos, "Dios se revela en la creación, en el espacio o en el lugar y no en el tiempo". Los indígenas no rechazan el tiempo, pero el valor primario es la conexión sagrada con el lugar.

- Los teólogos de la liberación promueven soluciones socialistas para alcanzar la libertad. Para los indígenas una solución socialista significa la confiscación de sus tierras colocadas bajo control estatal. Esto es inaceptable para los nativos americanos. Tinker ha citado la revolución sandinista en Nicaragua y su tratamiento de los indios Miskitos. Él ha reclamado que millares fueron reubicados lejos de sus lugares de origen, incluyendo algunos traídos para trabajar en las plantaciones del café en las montañas centrales. ${ }^{22}$ 
Importantes representantes de la teología indígena latinoamericana son Eleazar López Hernández de México y Domingo Llanque Chana del Perú. Hernández, un zapoteco de México, sostiene que el hecho de que los pueblos indígenas "ven la tierra como madre y no como medio de producción" ofrece una base para proteger el medio ambiente. Así, la cultura indígena puede ayudar a la cultura dominante a descubrir nuevos espacios para la diversidad y la humanidad. ${ }^{23}$

\section{Nuevo modelo para el siglo XXI: Paz justa}

Los dos modelos históricos legítimos de la guerra justa y el pacifismo ofrecen opciones muy limitadas para los activistas. Los críticos preguntan legítimamente: "¿No hay nada que podamos hacer para construir la paz, además de apoyar una guerra "justa" o no combatir? Curiosamente, esa cuestión se ha vuelto importante para los teóricos cristianos sólo en las últimas décadas. Las opciones limitadas ayudaron a generar el surgimiento de un nuevo modelo cristiano de construcción de la paz, "Just Peacemaking" (la Cultura de Paz justa o Paz justa). Se centra en un conjunto de medidas activas que los cristianos pueden apoyar en la construcción de un mundo más pacífico.

"Paz justa" se asocia principalmente con el fallecido Glen Stassen, profesor de teología en el Seminario Teológico Fuller evangélico en California. En un libro clave, publicado por primera vez en 1992, Glen Stassen argumentó que hay muchas cosas que los cristianos pueden hacer para promover la prevención y resolución de conflictos antes de que lleven a la guerra. Proclamando el camino de Cristo como "el modelo de autoridad para nuestra práctica ética", Stassen:

- consideraba a Jesucristo como el soberano de toda vida, no sólo la parte espiritual;

- definió el discipulado como siguiendo fielmente a Jesucristo en el momento presente;

- interpretó las enseñanzas de Jesús no como ideales, sino como prácticas concretas. ${ }^{24}$
Examinando el Sermón de la Montaña, Stassen rechazó explícitamente "la hermenéutica de la evasión". Por evasión entendía la interpretación de los mandatos en el Sermón como sólo ideales elevados, o sólo aplicables al clero o relevantes sólo a las relaciones interpersonales y no a la economía y la política. ${ }^{25}$

Específicamente, el simple establecimiento de la paz hace que las "iniciativas transformadoras" de Jesús sean su plataforma básica para la acción. Se basa en la experiencia del siglo XX de líderes espirituales como Gandhi y King que movilizaron la resistencia no violenta - marchas, manifestaciones, boicots y otros dramáticos actos de conciencia - contra la represión violenta. Se basa en las teologías de la liberación como un mensaje básico del Evangelio - la afirmación de que Jesucristo fue el Libertador, cuya misión básica era traer la liberación a los pobres y oprimidos de ambos sexos. Y se basa en normas internacionalmente reconocidas, como la Declaración Universal de Derechos Humanos. ${ }^{26}$ En su núcleo, el establecimiento de la paz tiene como objetivo ayudar a los cristianos a comprometerse activa y apasionadamente en los esfuerzos para conciliar el conflicto en sus iglesias, pero también a nivel comunitario, nacional e internacional.

Una característica clave del modelo Paz justa es su insistencia en la cooperación con otros elementos de mentalidad correcta en la sociedad. Eso significa primero que es ecuménico. El modelo es aplicable tanto a los católicos romanos como a los cristianos evangélicos y pentecostales. ${ }^{27}$ Deben trabajar en asociación. También pide explícitamente a los líderes cristianos que trabajen con la sociedad civil -es decir, con las asociaciones voluntarias locales y nacionales que buscan contribuir a la vida humana mediante la educación, el socorro a los indigentes y los enfermos, la potenciación de las mujeres y los niños, o la expansión de las oportunidades económicas. ${ }^{28}$ La cooperación con el gobierno o partes del gobierno también puede ser apropiada, dependiendo del gobierno. Pero no es un elemento esencial del modelo. La Paz justa no funciona contra el gobierno en circunstancias normales, pero debe preservar su capacidad de mantener la distancia apropiada del gobierno,

23 "Umbrales, Entrevista: Padre Eleazar López, 10 de febrero de 2017, chasque.net/umbrales/rev156/26_27.htm

24 Glen H. Stassen, ed., Just Peacemaking: the New Paradigm for the Ethics of Peace and War (2008), 1924

25 Just Peacemaking: Transforming Initiatives for Justice and Peace (1992), 33-34

26 Just Peacemaking (1992), 53-88

27 Just Peacemaking (2008), 17-19. Sobre la aplicación interreligiosa del modelo véase Susan Brooks Thistlethwaite, ed., Interfaith Just Peacemaking: Jewish, Christian, and Muslim Perspectives on the New Paradigm (2011)

28 Just Peacemaking (2008), 27-32 
recordando las palabras del salmista: "No pongas tu confianza en los príncipes" (Salmo 146) y la tradición profética de Amós, Jeremías, y Jesús.

Si bien se centra intensamente en la prevención de conflictos y en la conciliación del conflicto violento cuando estalla, Paz justa reconoce que la paz no es un simple estado final. El acuerdo negociado que pone fin a una convulsión violenta prolongada debe ser apoyado a mediano y largo plazo.

Debe estar respaldada por la promoción del respeto de los derechos humanos. Debe apoyarse promoviendo una representación justa de los grupos involucrados en la solución mediante un proceso razonablemente democrático. ${ }^{29}$ Así, mientras buscan la paz, los líderes cristianos deben defender el respeto a los derechos humanos y la política participativa. Después de que se alcance un estado de paz, los líderes cristianos deben trabajar con grupos de la sociedad civil y el gobierno para fortalecer el estado de derecho y para hablar en contra de los abusos contra los derechos humanos.

Un estado de paz también debe ser apoyado económicamente. Es improbable que la paz sobreviva si la actividad económica normal no se restaura y si los beneficios económicos no son compartidos con algún grado de equidad por las partes en conflicto. ${ }^{30}$ En general, la población debe sentirse comprometida con la paz porque existe una esperanza realista de mejorar sus vidas: puestos de trabajo, asistencia sanitaria, educación, así como oportunidades económicas para los agricultores, los pastores y los habitantes de las ciudades. Los líderes cristianos deben trabajar con la sociedad civil y el sector privado para promover programas que apoyen el crecimiento económico sostenible. De lo contrario, el conflicto puede estallar de nuevo.

\section{Modos de activismo de la paz cristiana bajo el nuevo modelo}

El modelo Paz justa abarca tres modos básicos de activismo en la consolidación de la paz: la abogacía organizada para la paz y la reconciliación, la promoción del diálogo entre las partes en conflicto y la acción directa no violenta en contra de la represión violenta y el uso injustificado de la fuerza. Estos modos se aplican tanto a un enfoque secular como religioso, pero los modos son algo diferentes en la práctica para los cristianos.

- Abogacía. El modo de abogacía se ejerce a través de la comunicación. La comunicación destinada a construir la paz en situaciones de conflicto puede tomar la forma de discursos, declaraciones públicas, editoriales y declaraciones de opinión. La comunicación puede ocurrir a través de la prensa, radio, televisión e Internet. Estos canales de comunicación pueden proporcionar al público información sobre el conflicto, incluyendo sus causas, evolución y posibles soluciones. Los mismos canales se pueden utilizar para exhortar a los participantes o funcionarios del gobierno a buscar una solución pacífica.

En los últimos años, los medios de comunicación social, como Facebook y Twitter, han mejorado enormemente la capacidad de los defensores para transmitir información al público y a los partidarios de ideas afines. Los defensores cristianos deben ser guiados por el relato de la verdad, pero deben contar la historia de una manera efectiva para dramatizar la urgencia de una solución pacífica. La neutralidad no siempre es importante para la abogacía efectiva. Los defensores pueden sentirse obligados a denunciar un patrón de injusticia que ocurre predominantemente en un lado o a criticar lo que consideran como el compromiso de un lado a una resolución por la fuerza. Sin embargo, la veracidad es esencial para la credibilidad.

- Promoción del diálogo entre las partes en
guerra. Un levantamiento violento local, el estallido de
una guerra civil o enfrentamientos militares entre dos
estados suelen estimular a individuos u organizaciones
a promover un arreglo pacífico. A veces los líderes
religiosos o las instituciones eclesiásticas asumen
ese papel, por lo general, pero no exclusivamente, en
situaciones de conflicto localizado. La promoción del
diálogo puede adoptar dos formas: los buenos oficios
y la mediación. Los buenos oficios significan ofrecer
ayuda informal a ambas partes para llegar a una
solución pacífica. Para ser eficaz, la parte que presta
buenos oficios debe ser vista como neutral. Dado que
la prestación de buenos oficios no implica un proceso
formal, la participación de los promotores de la paz




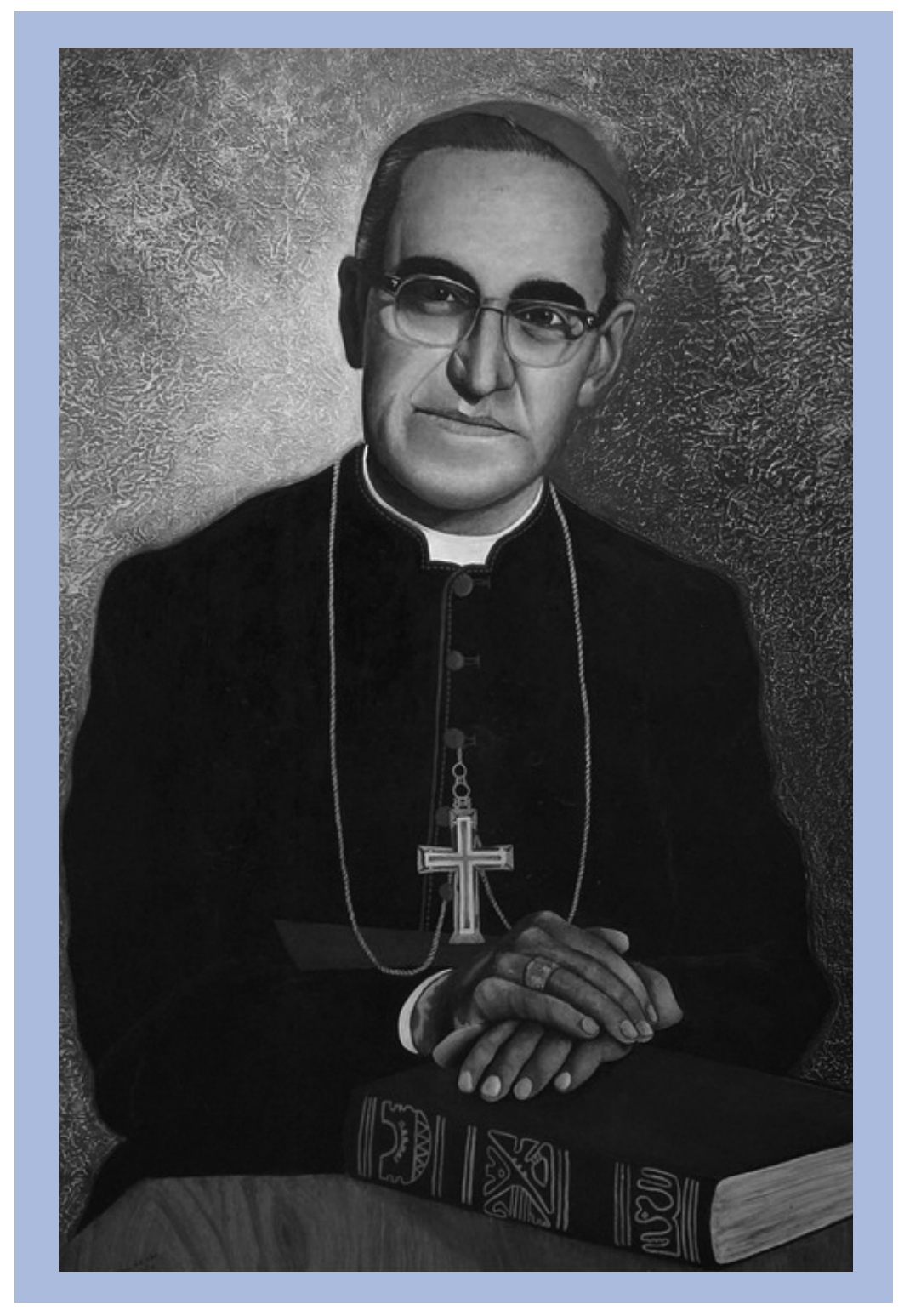

puede variar de intensa a episódica, dependiendo de sus relaciones con las partes en el conflicto y de las oportunidades que surjan. Los buenos oficios son muy apropiados para los líderes de la iglesia.

La mediación es un proceso más formal, normalmente basado en un acuerdo escrito con ambas partes. El mediador también debe ser visto como neutral. El papel del mediador es ayudar a las partes a encontrar una solución que satisfaga sus necesidades más esenciales. Por lo general, el mediador no propone una solución; hacerlo puede ser peligroso. Para ser duradera, la solución negociada debe ser propiedad de las partes. De lo contrario, los problemas con el acuerdo y la reanudación de la violencia serán imputados al mediador. La mediación suele involucrar a funcionarios gubernamentales, diplomáticos o representantes de organizaciones internacionales, pero la mediación cristiana puede ser apropiada para conflictos más localizados.

Unejemplodebuenos oficiosfueel trabajoen Nicaragua en la década de 1980 de CEPAD, el Comité evangélico para la ayuda y el desarrollo, para fomentar el diálogo entre las autoridades gubernamentales y YATAMA, el grupo paraguas de la resistencia indígena. ${ }^{31}$ Cooperó

31 Lederach, "Levels of Leadership," Luc Reychler y Thania Paffenholz, Peacebuilding: a Field Guide (2001), 152. 
con la Iglesia Morava y el gobierno en la creación de una Comisión de Conciliación. La Comisión negoció conversaciones sandinistas con un líder Miskito que condujo a la incorporación de YATAMA en el acuerdo que procedió a elecciones libres en 1989. Con respecto a la mediación, la organización católica laica Sant'Egidio medió con éxito las negociaciones entre el Gobierno de Mozambique y los rebeldes RENAMO que pusieron fin a la guerra civil en ese país en $1992 .{ }^{32}$

- Acción directa. Es improbable que la comunicación por sí sola resuelva los conflictos violentos, y las oportunidades de mediar entre ellos o proporcionar buenos oficios a las partes en conflicto son infrecuentes. La acción directa no violenta que moviliza segmentos clave de la población afectada puede influenciar a los participantes en la violencia para que cambien de rumbo. La acción directa a menudo implica la comunicación, pero, a diferencia de la abogacía, la atención se centra más en la acción que en la exhortación y la provisión de información.

Los actos de no violencia van desde una resistencia leve hasta medidas que corren el riesgo de una respuesta violenta. Ejemplos incluyen peticiones de reparación, socialización con los objetivos humanos de la violencia, negativa a pagar un impuesto como protesta contra la política, boicots, sentadas, marchas, manifestaciones, ralentizaciones laborales, abstenciones de trabajo, las huelgas contra los empleadores, las huelgas generales, la ocupación pacífica de las oficinas, la negativa a responder a los agentes de policía para moverse o dispersarse, incluida la resistencia pasiva al arresto (sentado o acostado) y el movimiento subrepticio y extrajudicial de las personas en peligro ("ferrocarril subterráneo" para facilitar el movimiento de esclavos fuera de la región meridional de los EEUU; proporcionar falsos documentos de recorrido para que los judíos escapen al nazismo). Pueden concebirse nuevas acciones, ya que el intelecto y la imaginación enfrentan nuevos desafíos y oportunidades.

Los constructores cristianos de paz, en particular, pueden emplear "signos proféticos" o "signos actos" para llamar la atención sobre la justicia de su causa y promover la transformación del conflicto. Los profetas hebreos, que respondían a lo que ellos veían como instrucciones de Dios, empleaban signos de advertencia para acercarse al conflicto y para divulgar los medios de evitarlo. Isaías, como una advertencia a Israel, caminó desnudo y descalzo durante tres años para retratar la ignominiosa marcha hacia el futuro exilio de los vecinos cercanos de Israel, Egipto y Cush, después de su conquista por Asiria (Isaías 20: 1-6). Jeremías puso un yugo sobre sus hombros para advertir al rey Sedequías que pronto estaría bajo el yugo de Nabucodonosor, a menos que ignorara la hipócrita optimismo de los falsos profetas (Jeremías 2728). El "signo acto" también puede ser diseñado para evocar la esperanza de un futuro pacífico. Jeremías compró un campo para retratar la confianza a cambio del exilio (Jeremías 32: 6-15). Ezequiel escribió "Judá" en un palo e "Israel" en otro y los sostuvo en su mano para retratar la posibilidad de reunificación después de generaciones de conflicto (Ezequiel 37: 15-23).

Los grupos cristianos contemporáneos a menudo participan en manifestaciones y marchas pidiendo una acción pacífica en lugar de una respuesta militar al conflicto internacional, llevando letreros y pancartas con lenguaje bíblico para protestar. Algunos grupos, sin embargo, emprenden acciones más inusuales y riesgosas que podrían ser descritas como "iniciativas transformadoras", compensando su falta de poder físico. ${ }^{33}$ Ejemplos contemporáneos:

- Una Marcha en Sayal. Desde 2013, el nuevo Sudán del Sur independiente ha sido devastado por la guerra civil. El Ejército Popular de Liberación de Sudán, que había arrebatado la autodeterminación y la independencia de Sudán, se disolvió efectivamente en las milicias tribales y cometió terribles abusos contra civiles de otras tribus - tortura, asesinato y violación en masa. En el 2016 un pastor en la ciudad principal de Yei movilizó a cientos de cristianos que desfilaron por las calles en saco blanco, pidiendo paz y arrepentimiento. En el clímax de la marcha, el pastor John Sebit, predicando del Libro de Jonás, afirmó que Dios estaba enviando un mensaje al pueblo para que se arrepintiera y buscara guía para lograr la reconciliación y la paz. ${ }^{34}$

- Desnudarse. Durante las últimas etapas de la guerra civil liberiana, dos mujeres luteranas

32 Dr. Jesús Romero Trillo, "El Papel de la Comunidad de Sant'Egidio en la resolución de conflictos" en Documentación Social: Revista de Estudios Sociales y Sociología Aplicada, en-feb 2008

33 Joseph Kip Kosek observa que la Comunidad de la Reconciliación concibió la no violencia como "teatro", uniendo "aspectos existenciales, rituales y espectaculares". Acts of Conscience (2009), 4

34 https://radiotamazuj.org/en/article/hundreds-christians-yei-streets-preaching-peace-and-repentance 
organizaron una rama liberiana de la Red de mujeres en la construcción de la paz (WIPNET), una asociación regional de África Occidental. El grupo liberiano creció rápidamente e invitó a las mujeres musulmanas a unirse. Después de presentar una petición de paz a las autoridades liberianas, se reunían diariamente en un lugar prominente de la capital para orar, cantar y bailar. A medida que su número aumentó, se aseguró una reunión con el presidente Charles Taylor, instigador de la guerra civil, y obtuvo una promesa de entablar conversaciones de paz en Ghana. Más tarde, cuando el progreso se desaceleró en las conversaciones, el grupo WIPNET bloqueó el acceso a la sala de reuniones para presionar a los negociadores. En un momento, Leymah Gbowee, el líder luterano, amenazó con desnudarse, para llamar la atención adicional a sus demandas. Ese paso, que recuerda al profeta Isaías, también invocó un tradicional tabú de África Occidental. Los hombres que ven la desnudez de una mujer después de la edad de procreación pueden ser considerados maldecidos. ${ }^{35}$ El mediador nigeriano aprovechó hábilmente esa amenaza y la presencia de las mujeres para presionar a los negociadores hacia el acuerdo final, lo que llevó a la salida de Taylor y al final de la guerra.

- Meterse en el camino. Desde 1990, los Equipos Cristianos de Acción por la Paz (ECAP) han participado en acciones no violentas en Irak, Palestina, Colombia y México.Su lema, "meterseen el camino" se refiere a su práctica de interponerse entre los agresores y sus víctimas desarmadas, "utilizando la práctica de la no violencia activa enseñada por Jesús". En Palestina la organización apoya la resistencia palestina no violenta a la ocupación, en coordinación con organizaciones israelíes e internacionales que trabajan por la paz. Sus rutinas incluyen acompañar a los niños a la escuela y monitorear la violencia de los colonos y las invasiones de soldados. ECAP también ha condenado la violencia palestina contra civiles israelíes.

En Colombia ECAP ha acompañado a varias comunidades a lo largo del río Opón, donde campesinos y pescadores fueron desplazados por enfrentamientos entre las Fuerzas de Autodefensa Colombianas (AUC), una milicia de derecha, y las Fuerzas Armadas Revolucionarias de Colombia (FARC). Los equipos tratan de prevenir la intimidación por parte de grupos armados y documentar los abusos contra los derechos humanos. En Irak, un miembro del ECAP murió y en Palestina varios han sido heridos por grupos de colonos. ${ }^{36}$ ECAP coopera con otros grupos, religiosos y seculares, que tienen objetivos similares. Entre los grupos seculares más conocidos están las Brigadas Internacionales de Paz y la Fuerza de Paz No Violenta.

\section{Directrices para los constructores cristianos de la paz}

Algunas de las siguientes directrices se aplican principalmente al modo de buenos oficios/mediación, pero otros son aplicables también a la acción directa y la abogacía. La lista se basa tanto en la práctica estándar de mediación secular como en las ideas de John Paul Lederach, quizás el constructor cristiano internacional más capacitado que trabaja hoy. ${ }^{37}$

1. La resolución de conflictos requiere un largo viaje. Lederach dice que alcanzar la paz en conflictos civiles complejos suele tardar una década. Ese fue el caso en Nicaragua, la ex Yugoslavia, Irlanda del Norte y Mozambique y mucho más en Colombia. La paciencia, la persistencia y el compromiso a largo plazo son esenciales en la mediación, pero también en campañas eficaces de acción no violenta y abogacía.

2. Humildad. Hacer la paz es un trabajo duro, y el fracaso es frecuente. Aquellos que proporcionan buenos oficios o mediación necesitan mostrar modestia acerca de su comprensión de los intereses y los objetivos de las dos partes. Los mediadores deben ser buenos oyentes. Los antagonistas necesitan percibir que sus agravios y objetivos se tienen en cuenta. El constructor de la paz debe evitar la arrogancia religiosa y moral. Demostrar humildad no significa falta de confianza. La confianza silenciosa surge de la bendición de Jesús de los pacificadores y la confianza en la presencia divina.

35 Leymah Gbowee,Mighty Be Our Powers (2011), 122-164.

36 Véase www.cpt.orgversión español.

37 Lederach, un menonita y profesor de construcción de paz, ha trabajado con gobiernos y movimientos de oposición en conflictos violentos en Nicaragua, Colombia, Somalia, Filipinas, Nepal e Irlanda del Norte. Reconcile, 154-156. 


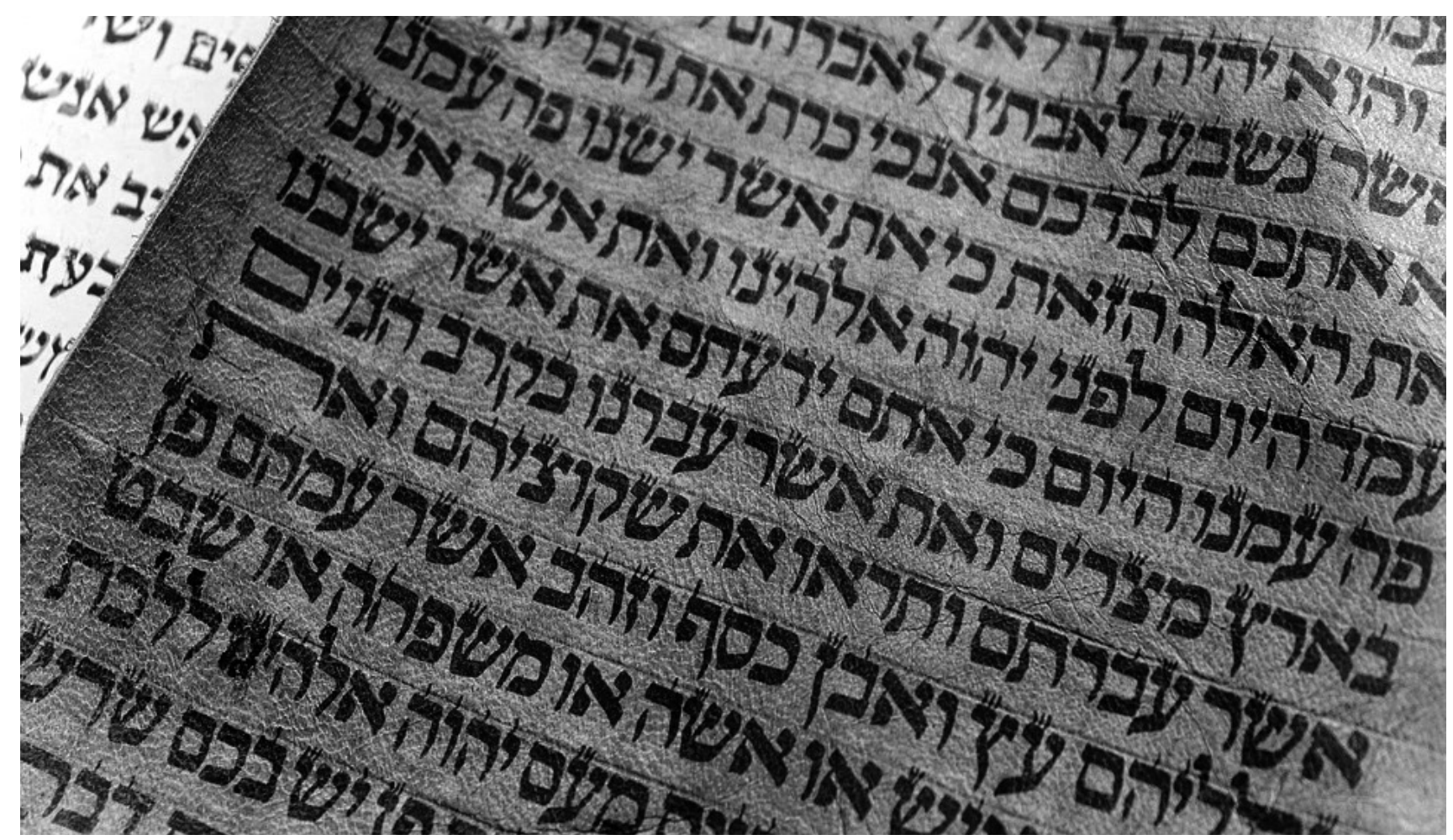

3. La consolidación de la paz es un esfuerzo de equipo. La promoción exitosa, la acción directa o los buenos oficios rara vez es una actividad de individuos. ${ }^{38}$ Los pacificadores necesitan un equipo para reunir información y ampliar la comprensión del contexto. El equipo adecuado proporciona apoyo mutuo y ánimo. Es particularmente importante incluir a las mujeres, reconociendo su potencial único de consolidación de la paz. Cuando la violencia contra la mujer es un factor, la inclusión de las mujeres en el grupo de consolidación de la paz es particularmente importante.

4. La oración juega un papel central en la construcción religiosa de la paz. Las oraciones públicas pueden aportar solemnidad y autodominio al ambiente de negociación. Ellas subrayan adecuadamente el dolor de aquellos que han perdido seres queridos. Más importante para los constructores de paz es su propia disciplina de oración sobre el resultado del proceso. Los constructores de paz eficaces buscan la dirección divina tanto en privado como en equipo. Se abren a ideas sobre cómo avanzar el proceso de paz, por ejemplo iniciativas transformativas que pueden inducir a los antagonistas a cambiar su perspectiva.

5. En los buenos oficios o en el modo de mediación, los constructores de paz buscan una relación personal con ambas partes. El fomento de la informalidad puede ayudar. Mantener conversaciones en una iglesia puede ejercer un efecto calmante sobre los líderes de una milicia o pandilla. La relación personal no significa aprobación o amistad. Los constructores de la paz a menudo tratan a la gente con sangre en sus manos. Ser neutral no significa imparcial. Todos los seres humanos tienen un grado de sesgo en el trato con otros. Los constructores de paz deliberadamente tratan de dejar de lado el sesgo personal para desempeñar un papel neutral con ambas partes. Ese es un axioma central de la mediación.

6. Una solución justa. Proporcionar buenos oficios o mediación no es proponer una solución. Esa es la tarea de las partes. Sin embargo, los promotores de la paz deben alentar a las partes a llegar a una en la que ambas partes estén de acuerdo en que

38 Por supuesto, una sola voz profética o acción a veces puede tener un gran impacto. 
se alcanza un grado esencial de justicia, incluso si ninguna de las partes alcanza todos sus objetivos. Los constructores de paz cristianos animan a las partes a considerar la visión bíblica de la justicia, que incluye la adjudicación de los males, pero también el perdón y la reconciliación. Contar historias de esperanza y reconciliación de la Biblia y las tradiciones locales puede ser útil.

7. Los constructores de la paz asumen riesgos. Aquellos que buscan persuadir a los jefes de las milicias, líderes de pandillas o funcionarios del gobierno represivos a negociar o detener las acciones violentas contra civiles pueden ser objeto de violencia. El líder norteamericano de derechos civiles John Lewis (más tarde el congresista Lewis) y varios otros líderes cristianos negros que marcharon por el fin de la discriminación racial en Selma, Alabama, en 1965 fueron golpeados por la policía hasta dejarlos inconscientes. El arzobispo Oscar Romero de El Salvador fue asesinado a tiros por los líderes de la milicia mientras celebraba la misa. Esos se oponían a su llamado a la justicia para los pobres y al fin de la viciosa guerra civil que los victimizaba.

\section{Relevancia del nuevo modelo para las iglesias de Centroamérica}

Para cerrar, existen varias situaciones de conflicto en las que la Paz justa podría ser la apropiada para las iglesias de Centroamérica.
- Reducir la violencia en las congregaciones y parroquias. Esto incluye la violencia contra las mujeres y los niños por parte de los esposos o parejas y la violencia entre las familias.

- Reducir la violencia de las pandillas. El Salvador, Honduras y Guatemala están plagados de pandillas, que reclutan a muchachos y muchachas y extorsionan masivamente a negocios en las ciudades y el campo. El reclutamiento expone a los jóvenes de ambos sexos a la violencia sexual y la muerte. La extorsión hace lo mismo para las familias dueñas de pequeñas empresas. La violencia de pandillas alimenta el éxodo de los jóvenes y empresarios de un país.

- Apoyar al campesinado contra la pérdida de tierras y los beneficios del gobierno debido a su supuesta oposición a las políticas gubernamentales, o contra la incautación de sus tierras por parte de los terratenientes ricos a través del mal uso del sistema judicial.

- Proteger los derechos de los pueblos indígenas contra la ocupación de tierras por parte de colonos de otras regiones del país y de las decisiones de los gobiernos (en los que carecen de representación) para tomar sus tierras y reubicarlos.

Son problemas desafiantes. Sin embargo, las resoluciones pacíficas que favorecen la justicia son fundamentales para la futura salud política y económica de la región. Corresponde a los líderes de la iglesia hacer frente a ellos con imaginación y coraje. 